\title{
The Environmental Risk of Heavy Metal Contaminated Soil as Raw
}

\section{Material for Making Ceramsites}

\author{
Yijian Feng ${ }^{1}$, Xiangyang Sun ${ }^{1}$, Zhong Zhong ${ }^{1}$ and Chi Zhang ${ }^{1 a}$ \\ 1Zhejiang Environmental Science \& Design Institute, Hangzhou, Zhejiang, 310007, China. \\ azchi@outlook.com
}

Keyword: Ceramsite; Calcination; Contaminated soil; Sludge; Heavy metal; Risk;

Abstract. Rapid and rough economic development in southeastern China has led brownfields come to be big problems. In this study, heavy metal contaminated soil and sludge were used as raw materials for ceramsites making in a simulated calcination system. Different recipes of raw materials for ceramites making were estimated by physical properties, heavy metal releasing risk. The results suggested lightweight ceramsites obtained under the recipe of " $30 \%$ municipal waste sludge and $70 \%$ contaminated soil" and "30\% chemical sludge and $70 \%$ contaminated soil". Leaching amount of heavy metals decrease more than $80 \%$ after calcinated. However, releasing risk of heavy metal still exist both in the flue gas and ceramites.

\section{Introduction}

Soil contamination is a broader and serious environmental problem in China as a result of industrialization $[1,2,3]$. Soil pollutants such as heavy metal, organic compounds and chlorinated pesticide are usually toxic and sometimes carcinogenic. Among them, heavy metal pollution is most widespread and difficult to remove [2]. The number of heavy metals contaminated sites is huge and keeps growing during the recent studies and statistics [4]. These heavy metals, which accumulate in soil over time, led to a number of environmental risks and waste of land resources.

At the same time, various remedial technologies have been applied to the treatment of heavy metals polluted soil, including stabilization/solidification, soil washing, phytoremediation, etc. However, stabilization and soil washing need to add a lot of chemicals, its high cost and secondary pollution problem should be carefully considered. Phytoremediation needs to take a long time, and it cannot be applied to high concentrations of heavy metals contaminated soil treatment. Therefore, it is still a research hotspot in new highly efficient technology of heavy metal contaminated soil remediation in recent years.

Industrial kiln co- pr $^{\circ}$ Cessing technology has developed rapidly in recent years as a sort of newly contaminated soil treatment technology and resource utilization method. Cement kiln co-pr ${ }^{\circ} \mathrm{Cessing}$ has been widely studied because of its huge capacity and rich experience in hazardous waste disposal. Ceramsite kiln has received less attention than cement kilns, but also has great development potential. Due to lower calcining temperature (ceramsite kiln is about $1200{ }^{\circ} \mathrm{C}$, cement kiln is about $1400{ }^{\circ} \mathrm{C}$ ) and higher additive portion of soil (ceramsite kiln is about $50-70 \%$, cement kiln is about 5-10\%), ceramsite kiln has lower energy consumption and disposal cost. However, lower calcining temperature and higher additive portion may lead the leaching heavy metals increase. Therefore, the releasing risk of residual heavy metals in the ceramsites is worth studying. In order to study the feasibility of heavy metal contaminated soil for making ceramsites, four kinds of different sludge (used as the accessories for gas-generation) and simulated contaminated soil of 
heavy metals were studied. Heavy metal leaching of ceramsites was investigated through standard leaching $\mathrm{pr}^{\circ} \mathrm{Cedure}$. And the environmental risk of ceramsite kiln co-pr ${ }^{\circ} \mathrm{Cessing}$ will also be discussed.

\section{Materials and Methods}

Sludge samples. Four kinds of sludge were used as accessories of ceramites making in this study. Each sludge is extensive in southeastern China, the sampling information is described as below:

a. Chemical sludge: sampled from the filter-press of a typical acetic anhydride factory in southeastern China;

b. Municipal sludge: sampled from a municipal waste water treatment plant in southeastern China (sludge of secondary sedimentation tank);

c. Dyeing sludge: flouring dyeing industry is typical in southeastern China. Dyeing sludge was sampled from a storage of a dyeing factory.

d. Titanium dioxide sludge: this type of sludge generated from the neutralization $\operatorname{pr}^{\circ}$ Cess of wastewater treatment system of a titanium dioxide factory.

The heavy metals concentration of each sludge was reflected in table1. As reflected, the heavy metals concentration was lower than the soil screening levels of contaminated soil (industrial land).

Table 1 . Heavy metals concentration in different sludge $[\mathrm{mg} / \mathrm{kg}]$

\begin{tabular}{|c|c|c|c|c|c|c|}
\hline Sludge type & $\mathrm{Cu}$ & $\mathrm{Zn}$ & $\mathrm{Pb}$ & $\mathrm{Cr}$ & $\mathrm{Ni}$ & Total \\
\hline T.D. sludge & 10.52 & 72.69 & 11.75 & 32.84 & 13.66 & 141.45 \\
\hline Dyeing sludge & 87.25 & 251.72 & 11.19 & 11.25 & 32.97 & 394.37 \\
\hline M.W. sludge & 65.17 & 256.29 & 20.19 & 43.19 & 27.02 & 411.88 \\
\hline Chemical sludge & 0.807 & 51.19 & N.D. & 0.830 & 1.361 & 55.36 \\
\hline
\end{tabular}

Notes: T.D. is short for titanium dioxide; M.W. is short for municipal wastewater.

Simulated soil contaminated with heavy metal. In order to study the feasibility heavy metals contaminated soil for ceramites making, simulated soil contaminated with heavy metal was prepared for the following tests. In order to guarantee the homology, clean nature soil was use as the basic part of the simulated soil. Certain amount of solution of $\mathrm{PbCl}_{2}, \mathrm{CuCl}_{2}, \mathrm{Ni}\left(\mathrm{NO}_{3}\right)_{2}, \mathrm{ZnCl}_{2}$ and $\mathrm{Cr}\left(\mathrm{NO}_{3}\right)_{2}$ were added as heavy metal pollutants. The heavy metal concentration of the simulated soil was refer to the soil screening levels (industrial land) of Zhejiang (DB33/T892-2013), i.e., concentration of $\mathrm{Cu}, \mathrm{Zn}, \mathrm{Pb}, \mathrm{Cr}$, Ni was $10000 \mathrm{mg} / \mathrm{kg}, 10000 \mathrm{mg} / \mathrm{kg}, 1200 \mathrm{mg} / \mathrm{kg}, 2500 \mathrm{mg} / \mathrm{kg}$, $300 \mathrm{mg} / \mathrm{kg}$, respectively. Before the subsequent tests, the simulated contaminated soil was $\mathrm{pr}^{\circ}$ Cessed by air-drying for two weeks.

Simulated ceramsite calcination system. The simulated ceramsite calcination system was composed of 2 muffle furnaces. According to our investigations, the full-scale ceramsite calcination system is mainly composed of drying pr ${ }^{\circ} \mathrm{Cess}$, preheat $\mathrm{pr}^{\circ} \mathrm{Cess}\left(350^{\circ} \mathrm{C}, 30 \mathrm{~min}\right)$ and calcination pr ${ }^{\circ}$ Cess $\left(500{ }^{\circ}{ }^{\circ} \sim 1050{ }^{\circ} \mathrm{C}, 45 \mathrm{~min}\right)$. In this experimental system for ceramites making, simulated soil contaminated with heavy metal and sludge were used as the main raw materials and accessories. The following $\operatorname{pr}^{\circ} \mathrm{Cesses}$ were described as below:

Step 1\#: Simulated contaminated soil and sludge were dried under $105^{\circ} \mathrm{C}$ for $24 \mathrm{~h}$, then they were grinded till particle size is less than $1 \mathrm{~mm}$.

Step 2\#: The grinded simulated contaminated soil and sludge were mixed by 7:3 (mass ratio), then distilled water was added until the mixture could be stuck in pellet by hand.

Step 3\#: The pellets were pre-heated in muffle furnace under $350^{\circ} \mathrm{C}$ for $30 \mathrm{~min}$. Then the 
pre-heated pellets were transferred to the another furnace for the next thermal $\mathrm{pr}^{\circ} \mathrm{Cess}$ (heating rate was kept at $15{ }^{\circ} \mathrm{C} / \mathrm{min}$ from $500{ }^{\circ} \mathrm{C}$ to $1050{ }^{\circ} \mathrm{C}$ ).

Step 4\#: The ceramsites were taken out for natural cooling, and then were used for analysis and leaching tests.

Performance tests of ceramites. In order to describe the results of calcination, weight and size of the pellets were measured before and after calcination, then volume expansion rate and density of ceramites were calculated.

Test of heavy metal volatilization. In order to evaluate the volatilization behavior of heavy metals, concentration of $\mathrm{Cu}, \mathrm{Zn}, \mathrm{Pb}, \mathrm{Cr}, \mathrm{Ni}$ in the pellets was determined before and after calcination. The volatilized amount of each heavy metal was calculated according to the conservation of mass.

Leaching tests. In order to study the leaching risk of heavy metals of ceramsites in reality, such as road paving materials, coarse aggregate of concrete, ceramsites were broken into less than $8 \mathrm{~mm}$ for SPLP (Synthetic precipitation leaching pr $^{\circ}$ Cedure) leaching tests as described by US EPA 1312.

Analysis. All samples for analysis of sludge and contaminated soil were dried under the temperature of $105{ }^{\circ} \mathrm{C}$, and were milled until particles size less than 100 mesh. Then, $0.300 \mathrm{~g}$ of the pretreated samples was used for digestion $\left(\mathrm{HNO}_{3} / \mathrm{HClO}_{4} / \mathrm{HF}\right)$ and atomic absorption spectrophotometry analysis. In order to determine the remaining heavy metals concentration in ceramsites, ceramsites were smashed by grinding machine (SM2000, Retsch, German) till particle size is less than 100 mesh, and then digested by $\mathrm{HNO}_{3} / \mathrm{HClO}_{4} / \mathrm{HF}$.

\section{Results and Discussions}

Characteristics of Ceramsites. Lightweight was one of the most important characteristics of ceramsites. After be calcined, all of the experimental groups changed in weight and appearance (as shown in table 2).

Table 2. Light-weight effect of each group

\begin{tabular}{|c|c|c|c|c|}
\hline Test Group & $\begin{array}{c}\text { Weight } \\
\text { loss rate }\end{array}$ & $\begin{array}{c}\text { Expansion } \\
\text { ratio }\end{array}$ & $\begin{array}{c}\text { Bulk density } \\
\left(\mathrm{kg} / \mathrm{m}^{3}\right)\end{array}$ & $\begin{array}{c}\text { Density } \\
\left(\mathrm{kg} / \mathrm{m}^{3}\right)\end{array}$ \\
\hline $\begin{array}{c}30 \% \text { T.D. } \\
\text { sludge+70\%Soil }\end{array}$ & $35.3 \%$ & $23.0 \%$ & 574 & 1096 \\
\hline $\begin{array}{c}30 \% \text { Dyeing } \\
\text { sludge+70\%Soil }\end{array}$ & $31.7 \%$ & $23.0 \%$ & 607 & 1160 \\
\hline $\begin{array}{c}30 \% \text { Chemical } \\
\text { sludge+70\% Soil }\end{array}$ & $37.0 \%$ & $49.3 \%$ & 461 & 880 \\
\hline $\begin{array}{c}30 \% \text { M.W. } \\
\text { sludge+70\% Soil }\end{array}$ & $35.7 \%$ & $49.5 \%$ & 471 & 1090 \\
\hline $100 \%$ Soil & $26.7 \%$ & $0 \%$ & 1001 & 2200 \\
\hline
\end{tabular}

After calcination, weight loss ${ }^{\circ}$ Ccurred in each pellet group. Compared with the " $100 \%$ soil" group, the result of the rest experimental groups demonstrated that the addition of sludge could accelerate mass loss. In other word, each kind of sludge can be used as accessory in the raw pellet for the light-weight performance of ceramites. In this respect, the " $30 \%$ chemical sludge+70\% soil" showed the best lightweight effect among these groups. On the other side, volume expansion took place in each group except the " $100 \%$ soil" group. This result demonstrated that gas-generation behavior happened in the inside of pellet during calcination. Among these groups, " $30 \%$ chemical sludge $+70 \%$ Soil" and "30\% M.W. sludge $+70 \%$ soil" exhibited the preferable volume expansion. 
Although the "30\% T.D. sludge+70\% soil" group reflect good weight loss rate $(35.3 \%)$ and good gas-generation ability, its volume ratio didn't meet the expectation. This result may caused by the poor compactness of pellet and the poor melting effect of this group. In other words, gas escape from gap of the surface too easily. Among these different ceramsites, the " $30 \%$ chemical sludge $+70 \%$ soil" and " $30 \%$ M.W. sludge $+70 \%$ soil" groups were better than rest in the aspect of bulk density values and density. This result may due to the better compactness and gas-generation ability of the raw pellets of these two groups. Besides, it was worth noting that bulk density of both groups were less than $500 \mathrm{~kg} / \mathrm{m}^{3}$, which satisfied with the bulk density requirement of super lightweight aggregate (GB/T17431.1-1998).

Environment risk of heavy metals. Relevant studies have revealed the behavior of heavy metals in some different thermal treatment systems, such as municipal solid waste incineration system, coordinated $\mathrm{pr}^{\circ}$ Cessing system of cement kiln and sludge incineration system [6,7]. Also, volatilization behavior of heavy metals in simulated ceramsite calcination system was captured and depicted in Figure 1.

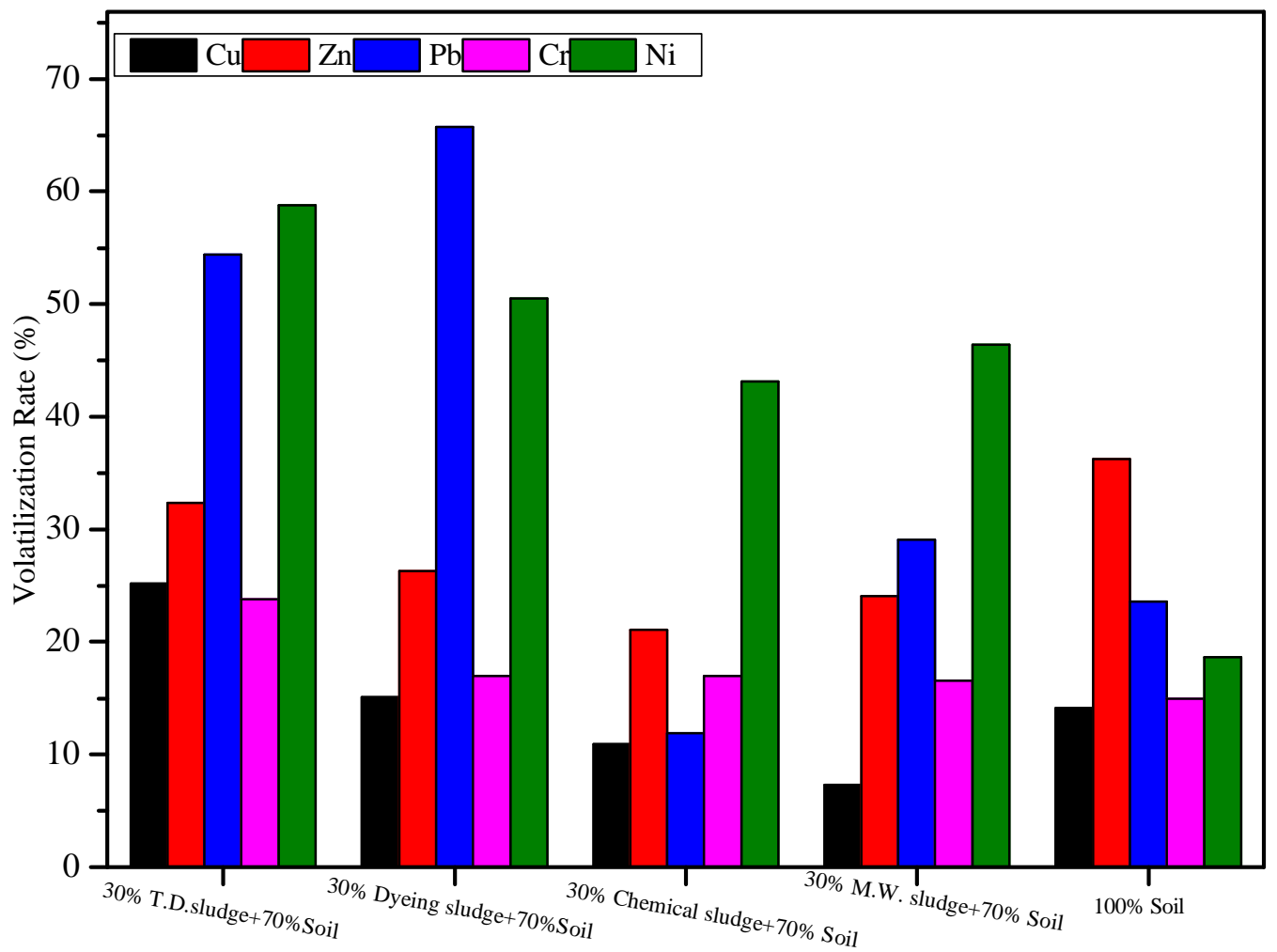

Figure 1. Volatilization rate of heavy metals

As exhibited in Figure $1, \mathrm{~Pb}$ and $\mathrm{Ni}$ tended to volatile from the pellet during calcination. Among these groups, the highest volatilization rate of $\mathrm{Pb}$ reached $65.7 \%$ in the group " $30 \%$ dyeing sludge $+70 \%$ soil". The highest volatilization rate of $\mathrm{Ni}$ reached $58.8 \%$ in the group "30\% T.D. sludge $+70 \%$ soil". Hence, when heavy metal contaminated soil was used for ceramites, $\mathrm{Pb}$ and $\mathrm{Ni}$ should be treat as key pollution factors. Except for $\mathrm{Pb}$ and $\mathrm{Ni}, \mathrm{Zn}$ volatilized from $21.1 \%$ to $36.3 \%$, $\mathrm{Cu}$ volatilized from $7.3 \%$ to $25.2 \%$, Cr volatilized from $15.0 \%$ to $23.8 \%$. This result illustrated that more than $50 \%$ of $\mathrm{Zn}, \mathrm{Cu}, \mathrm{Cr}$ remained in ceramsite of all groups. Although the volatilization ratio of $\mathrm{Cu}, \mathrm{Zn}$ was not as high as that of $\mathrm{Pb}$ and $\mathrm{Ni}$, it should be noted that, soil contaminated with $\mathrm{Zn}$ and $\mathrm{Cu}$ was generally of high level (because the screening level of $\mathrm{Cu}$ and $\mathrm{Zn}$ for industrial use is $10000 \mathrm{mg} / \mathrm{kg}$ ) in reality. Thus, the volatility quantity of $\mathrm{Zn}$ and $\mathrm{Cu}$ in this system should be also pay 
attention. As mentioned above, heavy metals volatilized during calcination $\mathrm{pr}^{\circ} \mathrm{Cess}$, the corresponding cleaning ability of flue gas should be enhanced. At the same time, due to the input concentration of heavy metal in this study was much higher than that of the traditional materials of ceramites, environment risk of the flue ash increased, which should be studied in the future.

Contrasting the heavy metals volatility of each group, certain difference could be found. For example, "30\% T.D. sludge $+70 \%$ soil" exhibited the highest volatility ratio of heavy metals than the others. This result also may also caused by its poor compactness of pellet. On the other hand, these group mixed with sludge showed higher volatility ratio of heavy metals than the "100\% soil" group, this result may due to the concentration anion in the sludge was higher than that of soil (Anion could promote the heavy metal volatility).

On the other hand, even if certain proportion of heavy metals has volatilized in ceramsite calcination system, the remaining amount in the ceramsite can' be ignored. The releasing risk of heavy metals of ceramsites was studied. According to the SPLP test results, solidification effect of calcination was confirmed (As described in Figure 2) when compared with the simulated contaminated soil of unburned.

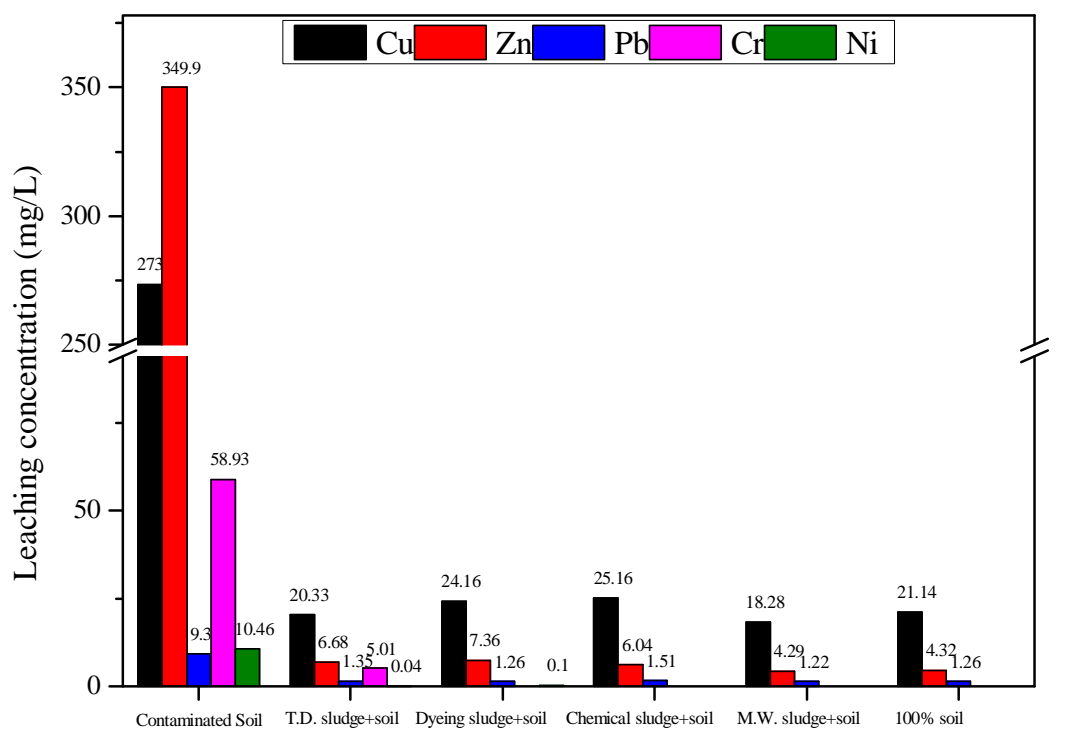

Figure 2. Result of SPLP tests

As reflected, the simulated contaminated soil(unburned) exhibited very high heavy metals leaching concentration. Without the effect of calcination, all of the leaching concentration of different heavy metal exceeded the identification standards of hazardous materials of China (GB5085.3-2007). Obviously, after calcinated, leaching concentration of heavy metals decreased obviously, and the leaching concentration were all under the identification standards of hazardous materials. This result might be due to two aspects. First, $\mathrm{SiO}_{2}$ will melt under the high temperature environment [8,9], a certain proportion of heavy metals can be solidificated and coated by ceramites after cooling. On the other hand, heavy metal oxidation took place during calcination, the activity of heavy metals weakened. As calculated, the average leaching concentration of ceramsites of $\mathrm{Cu}, \mathrm{Zn}$, $\mathrm{Pb}, \mathrm{Cr}, \mathrm{Pb}$ was $92.3 \%, 98.7 \%, 82.2 \%, 91.5 \%$ and $99.6 \%$ lower than that of the simulated contaminated soil of unburned, respectively. However, in these tests, leaching concentration of $\mathrm{Cu}$, $\mathrm{Zn}$, and $\mathrm{Pb}$ was still higher than the corresponding value of IV standard of groundwater (HJ610-2016). According to the results mentioned above, first, the stabilization effect of calcination was confirmed. Second, certain leaching risk of heavy metals still exist. Hence, feed concentration of heavy metals in the raw materials should be limited for the reason of environmental risk of 
ceramites.

\section{Conclusions}

Simulated contaminated soil and sludge were use as raw materials for ceramsites making in this study, and the heavy metal environmental risk was studied. According to the results, ceramsites of preferred lightweight performance could be obtained with the recipe of " $30 \%$ municipal waste sludge and $70 \%$ contaminated soil" and " $30 \%$ chemical sludge and $70 \%$ contaminated soil". Heavy metals $\mathrm{Pb}$ and $\mathrm{Ni}$ tend to volatilize in the experimental ceramsites calcination system, heavy metals emission risk should be treat as environmental $\mathrm{f}^{\circ} \mathrm{Cus}$ in practical application. The stability effect of heavy metals by calcination was confirmed according to the SPLP results. However, heavy metal releasing risk of ceramites could not completely eliminated (leaching concentration of $\mathrm{Cu}, \mathrm{Zn}$, and $\mathrm{Pb}$ was still higher than the corresponding value of IV standard of groundwater). According the mentioned above, screening $\operatorname{pr}^{\circ}$ Cees of the contaminated soil of heavy metals for make ceramites was necessary. Besides, flue gas purification system must be enhanced to control the emission risk of heavy metals in flue gas.

\section{Acknowledgement}

This work was supported by Zhejiang Science and Technology Research Grant (2017F10015) and Zhejiang Environmental Protection Research Grant (2015A025).

\section{Reference}

[1] S. Alker, V. Joy, P. Roberts, N. Smith: Environ. Plann. Manage. Vol.43 (2000), p. 43-69.

[2] Z.Li, Z. Ma, T.J. van der Kuijp, Z. Yuan, L. Huang: Sci. of Total Environ. Vol. 468 (2014), P. 843-853.

[3] X. L, Liu, Y. Wang, G. Luo, X. Chen, X. Yang, M.H.P Hall, R. Guo, H. Wang, J. Cui, X. He: Geoderma. Vol. 192 (2013) 50-58.

[4] K.S. Wang, K.Y. Chiang, C.C. Tsai, C.J. Sun, C.C. Tsai, K.L. Lin: Environ. Int. Vol. 26 (2001), P. 257-263.

[5] H. Zhang, P.J. He, L.M. Shao: Environ. Sci. Technol. Vol. 42 (2008), P. 6211-6217.

[6] M.A. Fernandez, L. Martinez, M. Segarra, J.C. Garcia, F. Espiell: Environ. Sci. Technol. Vol. 26 (1992), P. 1040-1047.

[7] C.H. Jung, T. Matsuto, N. Tanaka, T. Okada: Waste. Manage. Vol. 24 (2004), p. 381-391.

[8] T.W. Cheng, Y.S. Chen: Ceram. Int. 30 (2004), P. 343-349.

[9] R.D. Li, Y. Chi, S.Q. Li, L. Wang, J.H. Yan, K.F. Cen: Environ. Sci. Vol. 23 (2002), p.113-117. 